\title{
The role of the fibrocyte, a bone marrow-derived mesenchymal progenitor, in reactive and reparative fibroses
}

\author{
Alberto Bellini and Sabrina Mattoli
}

\begin{abstract}
Human fibrocytes are mesenchymal progenitors that exhibit mixed morphological and molecular characteristics of hematopoietic stem cells, monocytes and fibroblasts. They likely represent the obligate intermediate stage of differentiation into mature mesenchymal cells of a bone marrow-derived precursor of the monocyte lineage under permissive conditions. On in vitro stimulation with pro-fibrotic cytokines and growth factors, human fibrocytes produce large quantities of extracellular matrix components and further differentiate into cells identical to the contractile myofibroblasts that emerge at the tissue sites during repair processes and in some fibrotic lesions. Studies in various animal models of wound healing or fibrotic diseases have confirmed the ability of fibrocytes to differentiate into mature mesenchymal cells in vivo and have suggested a causal link between fibrocyte accumulation and ongoing tissue fibrogenesis or vascular remodeling in response to tissue damage or hypoxia. Fibrocytes synthesizing new collagen or acquiring myofibroblast markers have been detected in human hypertrophic scars, in the skin of patients affected by nephrogenic systemic fibrosis, in human atherosclerotic lesions, and in pulmonary diseases characterized by repeated cycles of inflammation and repair, like asthma. The presence of fibrocyte-like cells has been reported in human chronic pancreatitis and chronic cystitis. Similar cells also populate the stroma surrounding human benign tumors. The available data indicate that human fibrocytes serve as a source of mature mesenchymal cells during reparative processes and in fibrotic disorders or stromal reactions predominantly associated with a persistent inflammatory infiltrate or with the selective recruitment of monocytes induced by ischemic changes and tumor development. A deeper understanding of the mechanisms involved in fibrocyte differentiation in these pathological conditions may lead to the development of novel therapies for preventing detrimental tissue or vascular remodeling and metastatic progression of invasive tumors. Laboratory Investigation (2007) 87, 858-870; doi:10.1038/labinvest.3700654; published online 2 July 2007
\end{abstract}

KEYWORDS: asthma; atherosclerosis; fibrocytes; myofibroblasts; tissue repair; tumor

The fibrocytes ${ }^{1-5}$ are bone marrow-derived mesenchymal progenitors $^{6-9}$ that coexpress hematopoietic stem cell antigens, markers of the monocyte lineage and fibroblast products. ${ }^{1-6,10,11}$ They constitutively produce extracellular matrix (ECM) components as well as ECM-modifying enzymes, ${ }^{1-3,5,11}$ and can further differentiate into myofibroblasts both in vitro and in vivo under permissive micro-environmental conditions. ${ }^{3,5,10,11}$ There is increasing evidence that these cells contribute to the new population of fibroblasts and myofibroblasts that emerge at the tissue site during normal $^{1,3,6}$ or aberrant ${ }^{12}$ wound healing, in ischemic or inflammatory fibrotic processes, ${ }^{8,9,11,13-24}$ and as part of the stromal reaction to tumor development. ${ }^{13,24-32}$ This review will focus on the origin of human fibrocytes and their involvement in the pathogenesis of reactive and reparative fibroses in human diseases.

\section{HEMATOPOIETIC ORIGIN AND MESENCHYMAL PROPERTIES OF HUMAN FIBROCYTES Origin and Phenotypic Characteristics}

The term fibrocyte was first used in 1994 to define a subpopulation of leukocytes that accumulate at sites of tissue injury and show fibroblast properties. ${ }^{1}$ In the initial report, fibrocytes were found to express the hematopoietic stem cell/ progenitor marker CD34, the leukocyte common antigen CD45 (a pan-hematopoietic marker) and several markers of the monocyte lineage in conjunction with vimentin and collagens. ${ }^{1}$ The phenotypic characteristics of these cells were 
further evaluated in subsequent studies ${ }^{3,5,10-12,23,33-35}$ and the markers of human fibrocytes are shown in Table 1.

Bucala and co-workers initially estimated that fibrocytes comprise $0.1-0.5 \%$ of the 'circulating' population of nonerythrocytic cells on the basis of the number of fibrocytes isolated from cultures of peripheral blood mononuclear cells, ${ }^{1,2}$ but additional experiments from the same group ${ }^{3}$ and from other investigators ${ }^{4,5,10,23}$ revealed that human fibrocytes may not be present in the peripheral blood as such and may originate from a circulating precursor. The most recent data suggest that fibrocytes mature from a subpopulation of $\mathrm{CD}_{14}{ }^{+}$peripheral blood mononuclear cells ${ }^{3-5,10,23}$ that express the receptors for the $\mathrm{Fc}$ portion of immunoglobulin G (IgG) Fc $\gamma$ RI (CD64) and Fc $\gamma$ RII (CD32) and do not express Fc $\gamma$ RIII (CD16) $)^{5,9,10}$ (Table 1). Therefore, circulating fibrocytes precursors may be present in a small fraction of the $\mathrm{CD} 14^{+} \mathrm{CD} 16^{-}$subset of human mononuclear cells that bear the CC chemokine receptor (CCR) 2 on their surface and are analogous to the murine Ly- $6 \mathrm{C}^{\text {high }}$ $\mathrm{CCR} 2^{+}$mononuclear cells, expressing low levels of the $\mathrm{CX}_{3} \mathrm{C}$ chemokine receptor $1 .^{38-40}$ This subset constitutes an immature subpopulation of cells that are normally present in the circulation and have been termed 'inflammatory' monocytes. ${ }^{38}$ In absence of inflammation, they likely serve to replenish the tissue-resident macrophage and dendritic cell populations after an initial differentiation into different subtypes of monocytes before they enter the tissues. ${ }^{38}$ During inflammatory processes, they are released in high number from the bone marrow into the peripheral blood and directly migrate to inflamed sites, predominantly through a CCR2mediated signaling pathway. ${ }^{38-40}$ Once migrated to the tissue sites, most of these precursors are thought to differentiate

Table 1 Markers of cultured human fibrocytes

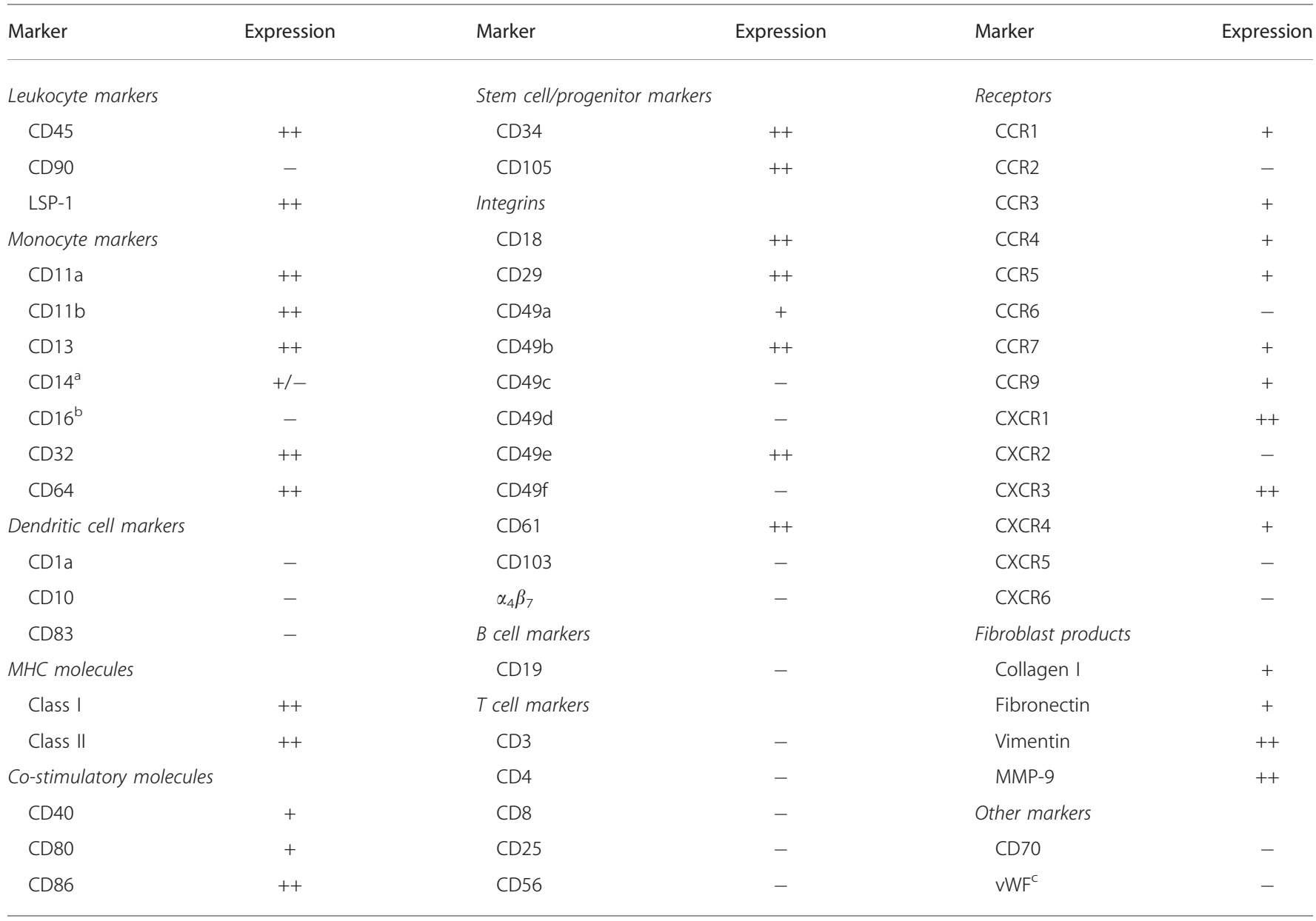

The symbols represent no expression (-), marginal or no expression (+/-) and increasing level of expression (+, ++$)$, and have been arbitrarily assigned to each marker on the basis of published data. ${ }^{1-5,10,11,17,23,36,37}$

${ }^{a}$ Although some studies ${ }^{2-5,11,17}$ have confirmed the initial report ${ }^{1}$ that human mature fibrocytes do not express CD14, subsequent serial phenotypic analyses of these cells in culture have revealed that fibrocytes downregulate to various extent, but may still retain $\mathrm{CD}_{14}$ expression as they mature from $\mathrm{CD}^{+} 4^{+}$monocytes. ${ }^{10,23}$ Actually, the apparent lose of CD14 expression in previous studies ${ }^{2-5,11,17}$ might be explained with the use of anti-CD14 antibodies to deplete 'contaminating' cells before harvesting fibrocytes from cultures of peripheral blood mononuclear cells.

${ }^{\mathrm{b}}$ Not expressed by 'inflammatory' monocytes. ${ }^{38,39}$

c von Willebrand factor (endothelial cell marker). 
into inflammatory macrophages or acquire dendritic cell-like cell characteristics, ${ }^{38,39}$ possibly after passing through an intermediate phenotype. ${ }^{38}$ However, the immature subpopulation of $\mathrm{CD}_{1} 4^{+}$mononuclear cells also contains a mixture of other committed precursors or multipotent precursors, which can differentiate into a number of cells different from macrophages and dendritic cells (eg, myoblasts, osteoblasts, chondrocytes, adypocytes, epithelial cells, endothelial cells, neuronal cells and liver cells) under certain permissive conditions. ${ }^{41,42}$ Human fibrocytes probably represent the obligate intermediate stage of differentiation of one of these precursors of the monocyte lineage into mature fibroblasts and myofibroblasts at the tissue sites.

Like hematopoietic progenitors ${ }^{43,44}$ and the $\mathrm{CD} 14^{+}$ $\mathrm{CD}_{16}{ }^{-}$subset of mononuclear cells ${ }^{38}$ from which they appear to originate in vitro, human fibrocytes express several CCRs and CXC chemokine receptors (CXCRs), including CCR7 and CXCR4, ${ }^{3,5}$ but show a downregulation of CD14 and CCR2 expression as they mature from the CD14 ${ }^{+}$ mononuclear cells $s^{3,5,10,33}$ (Table 1). The maturation process is also associated with the early upregulation of hematopoietic stem cell/progenitor markers that are no longer expressed by mature monocytes, ${ }^{42}$ such as $\mathrm{CD} 34^{23}$ and $\mathrm{CD} 105^{5}$ (Table 1 ). The hypothesis that fibrocytes, like some dendritic cells subsets, derive from precursors of the monocyte lineage is supported by the evidence that these cells express the major histocompatibility complex class I and class II and the costimulatory molecules CD80 and CD86 (Table 1), ${ }^{1,5,10,34,35}$ exhibit antigen-presenting activity ${ }^{34}$ and activate both $\mathrm{CD} 4^{+}$ and $\mathrm{CD}^{+}{ }^{+}$T lymphocytes. ${ }^{34,35}$ However, they lack specific markers of monocyte-derived dendritic cells such as CD1a, CD10 and CD83 (Table 1).

The combination of collagen production and expression of CD45 or one of the hematopoietic (CD34) or myeloid antigens (CD11b, CD13) is considered as a sufficient criterion to discriminate fibrocytes from leukocytes, dendritic cells, endothelial cells and tissue-resident fibroblasts in vitro and in vivo. ${ }^{1,3,5,10-12,23}$ Fibrocytes can be distinguished from circulating or tissue-resident mesenchymal stem cells/multipotent mesenchymal stromal cells, because the latter cells express fibroblast products but are CD90-positive and do not express CD34 or CD45 or the monocyte markers. ${ }^{45,46}$ Human mesenchymal stem cells residing in the bone marrow can express CD34, CD45 and CXCR4 to various extents, but remain negative for monocyte markers. ${ }^{47}$

\section{Development and Mesenchymal Properties}

Although initial studies demonstrated the development of fibrocytes from peripheral blood mononuclear cells after 10-14 days of culture in media containing high concentrations of serum, ${ }^{1-4}$ subsequent investigations revealed that human $\mathrm{CD}^{+} 4^{+}$mononuclear cells differentiate into fibrocytes within 3 days in serum-free media. ${ }^{5,10,48}$ Moreover, whereas the fibrocytes that emerge in serum-free cultures of peripheral blood mononuclear cells already express high levels of prolyl 4-hydroxylase, the enzyme required for the synthesis of new collagen, ${ }^{10}$ fibrocytes developed in serumsupplemented media show low prolyl 4-hydroxylase activity in comparison with mature fibroblasts. ${ }^{36}$ However, fibrocytes are immature mesenchymal cells that do not produce large amounts of collagenous proteins or other ECM components until they differentiate into mature fibroblasts and myofibroblasts, ${ }^{11}$ but are an important source of ECM-degrading enzymes, primarily matrix metalloproteinase-9 (MMP-9). ${ }^{37}$

Several factors affect the development of fibrocytes from the $\mathrm{CD} 14^{+}$precursor and the differentiation of fibrocytes into mature mesenchymal cells. ${ }^{3,5,10-12,23,48}$ Direct contact between peripheral blood CD14 ${ }^{+}$mononuclear cells and $\mathrm{T}$ lymphocytes in co-cultures and stimulation of peripheral blood $\mathrm{CD} 14^{+}$mononuclear cells with transforming growth factor- $\beta_{1}\left(\right.$ TGF- $\left.\beta_{1}\right)$ (either added as a recombinant protein or derived from $\mathrm{CD} 14^{-}$mononuclear cells) increase the yield of fibrocytes. ${ }^{3,12}$ Platelet-derived growth factor (PDGF), ${ }^{23}$ interleukin (IL)- 4 and IL- $13^{48}$ also promote the differentiation of $\mathrm{CD}_{1} 4^{+}$mononuclear cells into fibrocytes. By contrast, stimulation of CD64 or CD32 by aggregated IgG or serum amyloid P (SAP) inhibits the development of fibrocytes from $\mathrm{CD}_{14}{ }^{+}$mononuclear cells. ${ }^{10} \mathrm{SAP}$ is a constitutive serum protein in most species and it has been identified as the active factor in serum that inhibits fibrocyte differentiation from the $\mathrm{CD} 14^{+}$mononuclear cells in serum-supplemented cultures. ${ }^{5,10}$ This molecule, which belongs to the pentraxin family of autacoids, is produced by the liver and its levels increase at tissue sites only during the early phase of inflammatory reactions associated with the extravasation of serum proteins, being rapidly cleared or inactivated at a later stage. ${ }^{5,10,48}$ Pro-inflammatory cytokines like interferon- $\gamma$ (IFN $\gamma$ ) and IL-12 inhibit the differentiation of fibrocytes from $\mathrm{CD} 14^{+}$mononuclear cells in serum-free media. ${ }^{48} \mathrm{IL}-1 \beta$ does not affect the maturation of fibrocytes from the monocyte precursors, ${ }^{48}$ but induces proliferation of mature fibrocytes and reduces the release of collagens from these cells. $^{2}$

Once fibrocytes have completed their maturation from $\mathrm{CD}_{14}{ }^{+}$mononuclear cells, further differentiation into cells ultrastructurally and phenotypically similar to mature fibroblasts and myofibroblasts is promoted by stimulation with TGF- $\beta_{1}{ }^{3,11}$ and endothelin-1 (ET-1). ${ }^{11}$ The resulting cell population produces much more collagens and fibronectin than fibrocytes, ${ }^{3,11}$ express the myofibroblast marker $\alpha$ smooth muscle actin ( $\alpha$-SMA), ${ }^{3,11,19}$ and downregulate the expression of CD34 and CD45. ${ }^{11,19}$ Spontaneous differentiation of fibrocytes into $\alpha$-SMA ${ }^{+}$cells also occurs, albeit to a much lesser extent, in unstimulated cultures, ${ }^{3,5,10,11}$ particularly in serum-free media ${ }^{10,11}$ and may be due to the autocrine production of TGF- $\beta_{1}{ }^{2}$ It is still unclear as to whether the myofibroblasts that mature from fibrocytes retain their ability to present antigens and activate certain $\mathrm{T}$ cell subsets. The recent observation that fibrocytes can transform into adipocytes when cultured under adipogenic conditions ${ }^{33}$ 
indicates that these cells have the potential to differentiate into other mesenchymal cell types, in addition to fibroblasts and myofibroblasts. The fibrocyte to adipocyte differentiation is associated with the re-expression of CCR2 and is inhibited by stimulation with TGF- $\beta_{1}{ }^{33}$

\section{Supporting Evidence from Animal Studies} Bone marrow origin of fibrocytes

A number of independent studies in chimeric mice have formally demonstrated the bone marrow origin of tissue fibrocytes $^{6-9,18}$ and of their precursors in the peripheral blood ${ }^{7}$ by using various markers of donor cells in the irradiated host, following bone marrow transplantation. An earlier study ${ }^{1}$ failed to obtain similar results in sex-mismatched bone marrow chimera mice, probably because total body irradiation with only 800 rads was not sufficient to ablate the bone marrow cell population in the female recipients before transplantation of the bone marrow from male donors. ${ }^{6,18}$

\section{Mechanisms by which fibrocytes populate peripheral organs} Tracking experiments in murine models of wound healing ${ }^{3}$ and chronic allergic asthma ${ }^{11}$ have demonstrated that intravenously injected fibrocytes rapidly migrate to wounded or chronically inflamed sites and localize to areas of ongoing ECM deposition. ${ }^{3,11}$ However, data from three independent animal studies ${ }^{9,20,23}$ suggest that this may not be the mechanisms by which fibrocytes populate peripheral organs, because the in vivo differentiation of fibrocytes from the circulating precursors may mainly occurs at the tissue sites and not in the peripheral blood. In the first study, ${ }^{9}$ fibrotic cardiomyopathy with global ventricular dysfunction was induced in mice by multiple daily episodes of brief coronary artery occlusion. The fibrotic process was associated with a marked and prolonged induction of the production of CCR2 ligands in the cardiac tissue, recruitment of monocytes from the peripheral blood and subsequent accumulation of $\mathrm{CD} 45^{+} \mathrm{CD} 34^{+}$fibrocytes that expressed a canonical cardiac fibroblast marker and acquired in part the myofibroblast marker $\alpha$-SMA. Daily treatment of mice with the inhibitor of fibrocyte differentiation SAP, while the animals were subjected to multiple daily episodes of brief coronary occlusion, inhibited the emergence of fibrocytes at the tissue site and markedly reduced the accumulation of myofibroblasts without affecting the nature and magnitude of the inflammatory response or the production of chemokines. The most likely explanation of these results is that the persistently high levels of active SAP interfered with the development of fibrocytes from the monocyte precursors taken up during the inflammatory response in the same manner as it occurs in vitro, when peripheral blood mononuclear cells are cultured in presence of serum. ${ }^{5,10}$ The second study ${ }^{20}$ used neonatal animal models of hypoxia-induced pulmonary vascular remodeling to evaluate the possible role of fibrocytes in the pathogenesis of chronic pulmonary hypertension. In experiments where circulating monocytes/macrophages of chronically hypoxic rats were selectively labeled in vivo, the labeled cells were subsequently identified in the remodeled adventitial layer of the pulmonary arteries. Many of these cells, expressing CD45 and the monocyte markers CD14 and $\mathrm{CD} 11 \mathrm{~b}$, progressively acquired the ability to synthesize new collagen while retaining expression of CD45 and CD11b. A substantial proportion of the cells expressing CD45 and monocyte markers also showed $\alpha$-SMA immunoreactivity in vivo. These observations suggest that fibrocytes matured in the adventitial layer from the monocyte precursors taken up from the circulation and started to differentiate into myofibroblasts. The hypothesis that fibrocytes mature from the circulating precursor at the tissue site is also supported by the results of the third study by Varcoe et $a l^{23}$ who traced the path of the circulating cells that contributes to vascular remodeling in an ovine model of carotid artery intimal hyperplasia induced by vascular graft implantation. A subpopulation of the labeled circulating leukocytes that infiltrated the intima in vivo progressively acquired the fibrocyte phenotype $\left(\mathrm{CD} 45^{+} \mathrm{CD} 34^{+}\right.$vimentin $\left.^{+}\right)$and showed $\alpha$-SMA immunoreactivity during the remodeling process.

Interestingly, Moore et al ${ }^{18}$ observed the emergence of $\mathrm{CD} 45^{+} \mathrm{CD} 13^{+}$fibrocytes, expressing collagen I gene and protein, in 10/14-day serum-free cultures of minced lung explants or bronchoalveolar lavage cells from mice with pulmonary inflammation and interstitial fibrosis induced by the intratracheal instillation of a toxicant, fluorescein isothiocyanate (FITC). Whether the lung explants or the bronchoalveolar lavage cell population contained fibrocytes or other cells of the monocyte lineage before being placed in culture is unknown. Much less fibrocytes emerged in cultures of minced lung tissue from mice lacking CCR2, which also showed a significant reduction in the fibrotic changes induced by FITC exposure. Transplantation of bone marrow cells from CCR $2^{+} /^{+}$into lethally irradiated CCR2 $2^{-1-}$ mice restored the ability to grow fibrocytes from minced explants of the injured lung and susceptibility to FITC-induced pulmonary fibrosis. The $\mathrm{CD}_{4} 5^{+} \mathrm{CD} 34^{\text {low }}$ collagen $\mathrm{I}^{+}$cells emerging in cultures of minced lung tissue initially showed CCR2 expression, but this receptor was lost when fibrocytes were allowed to mature further in vitro for additional 7 days. These observations, ${ }^{18}$ and further data from the same group, ${ }^{21}$ suggest that the CCR2 ligands may play a pivotal role in the accumulation of fibrocytes during a fibrotic process triggered by a toxicant-induced inflammatory reaction in the lungs. The findings may be relevant to human fibrotic diseases, because the recruitment of human fibrocyte precursors $\left(\mathrm{CD} 14^{+} \mathrm{CD}^{-}\right.$mononuclear cells) into inflamed tissues, like the recruitment of the murine counterpart of inflammatory monocytes, is critically dependent on CCR $2 .^{39,40}$

Other studies have demonstrated an important role of the ligand of CXCR4, CXC chemokine ligand 12 (CXCL12), ${ }^{17}$ and of one of the ligands of CCR7, CC chemokine ligand 21 
(CCL21), ${ }^{19,22}$ in the accumulation of fibrocytes in animal models of injury-induced pulmonary ${ }^{17,19}$ and renal fibrosis. ${ }^{22}$ Because both human fibrocytes ${ }^{3,5}$ and the $\mathrm{CD} 14^{+} \mathrm{CD} 16^{-}$ subset of mononuclear cells ${ }^{38}$ from which they appear to originate in vitro express CXCR4 and CCR7, these ligands may be involved in the accumulation of fibrocytes in some human fibrotic diseases.

\section{Phenotypic changes associated with the differentiation of fibrocytes into myofibroblasts in vivo}

Two studies from our laboratory have provided key information on the ability of fibrocytes to differentiate into mature mesenchymal cells in vivo and on the phenotypic changes associated with the differentiation process. ${ }^{6,11}$ In an animal model of wound healing, ${ }^{6}$ numerous $\mathrm{CD} 45^{+} \mathrm{CD} 13^{+}$ collagen $\mathrm{I}^{+}$fibrocytes of bone marrow origin could be isolated from digested fragments of wounded tissue between 4 and 7 days post-wounding, when inflammatory cells of the monocyte lineage are particularly abundant in the granulation tissue. ${ }^{49}$ Collagen I expression was confirmed by demonstrating transcription from the pro-collagen I gene in the isolated cells. Whereas only a few fibrocytes showed $\alpha$-SMA immunoreactivity at day 4 post-wounding, about $59 \%$ of these cells, on the average, were found to express the myofibroblast marker at day 7 post-wounding. The expression of $\alpha$-SMA was confirmed at the gene level. The differentiation of fibrocytes into myofibroblast-like cells occurred in concomitance with increased production of TGF- $\beta_{1}$ in the wounded tissue and was associated with a progressive downregulation of the expression of CD34 and CD45, with only $21 \%$ of the $\alpha-\mathrm{SMA}^{+}$fibrocytes staining positively for CD34 at day 7. Similar CD $45^{+}$CD $34^{-} \alpha-\mathrm{SMA}^{+}$cells of bone marrow origin where subsequently observed by another group at the same point in time post-wounding. ${ }^{50}$ In the other study from our laboratory, ${ }^{11}$ labeled $\mathrm{CD} 34^{+}$collagen $\mathrm{I}^{+} \alpha-\mathrm{SMA}^{-}$fibrocytes were found to acquire the CD34 ${ }^{-}$ collagen $\mathrm{I}^{+} \alpha$-SMA ${ }^{+}$phenotype within $24 \mathrm{~h}$ from their localization in the subepithelial area of the airway wall of mice, where repeated cycles of allergen-induced inflammation caused excessive deposition of ECM molecules and thickening of the lamina reticularis. Taken together, the results of these studies directly demonstrate that fibrocytes can differentiate into mature myofibroblasts at the tissue sites during normal wound healing as well as in conditions where repeated inflammatory reactions prevent effective tissue repair and lead to fibrotic changes. They also indicate that, during this differentiation process, fibrocyte-derived myofibroblasts rapidly lose the surface markers that are currently used to distinguish them from fibroblast-derived myofibroblasts or other resident mesenchymal cells in vivo.

\section{Causal link between fibrocyte accumulation and tissue fibrogenesis}

Evidence of a causal link between the accumulation of fibrocyte at injured sites and ongoing tissue fibrogenesis or vascular remodeling has been provided in various animal models of pulmonary, ${ }^{11,17,19,51}$ renal $^{22}$ and vascular diseases $^{20,23}$ and in the model of ischemic cardiomyopathy mentioned above. ${ }^{9}$ In these models, the fibrocytes appeared to contribute to the new population of collagen-producing cells ${ }^{9,11,17,19,20,22,23}$ and/or $\alpha$-SMA ${ }^{+}$cells ${ }^{9,11,19,20,23}$ that emerged at the injured tissue sites during the reactive/ reparative fibrotic process. Inhibition of fibrocyte accumulation by different means resulted in reduced collagen deposition $^{9,17,19,20,22,23,51}$ and reduced accumulation of myofibroblasts, ${ }^{9,17,19,20,23}$ supporting the hypothesis that lesional fibroblasts and myofibroblasts mature at least in part from fibrocytes. However, fibrocytes themselves produce a number of cytokine and growth factors ${ }^{2,37}$ that induce angiogenesi ${ }^{37}$ or fibroblast hyperplasia ${ }^{36}$ and promote the release of ECM molecules from resident tissue fibroblasts. ${ }^{36}$ Therefore, the observed correlations between fibrocyte accumulation and ongoing tissue remodeling may also reflect the pro-fibrotic activity of these cells.

\section{FIBROCYTE INVOLVEMENT IN HUMAN DISEASES Hypertrophic Scars and Keloids}

Hypertrophic scars and keloids represent two different forms of aberrant wound healing and frequently develop as a consequence of extensive burn injury. ${ }^{52-55}$ Hypertrophic scars are predominantly characterized by the presence of narrow and widely spaced collagen fibrils that are arranged to form a nodular structure. ${ }^{54,55}$ In contrast, keloids contain thick collagen fibers composed of numerous fibrils packed together. ${ }^{54,55}$ Although an inflammatory infiltrate is present in both forms of excessive scarring, it is particularly evident in young lesions and in the hypertrophic form, and it is composed of T lymphocytes, monocytes and dendritic-like cells. ${ }^{55}$ The nodules of hypertrophic scars show enhanced expression of TGF- $\beta_{1}$ mRNA, ${ }^{56}$ the presence of cells actively synthesizing new collagens (pro-collagen I and III) ${ }^{56}$ and numerous $\alpha$ SMA myofibroblasts, which are also thought to cause the typical scar contractures. ${ }^{54}$ Aiba and Tagami ${ }^{57}$ detected dermal spindle-shaped cells coexpressing CD34 and proline4-hydroxylase, the enzyme critically involved in collagen synthesis, in scars where the inflammation began to subside. By examining the immunohistochemical characteristic of dermal spindle-shaped cells at various stages of hypertrophic scar and keloid development, they observed that CD34 expression decreased over time, whereas the expression of proline-4-hydroxylase increased. In a more recent study, Yang et $a l^{12}$ identified spindle-shaped cells coexpressing the leukocyte-specific protein-1 (LSP-1) and pro-collagen I in postburn hypertrophic scars. Similar cells also populated mature scars, but their density was a significantly lower than in hypertrophic scars. LSP-1 is one of the leukocyte markers expressed by fibrocytes (Table 1) and it is retained more stably than the transiently expressed CD34. Thus, taken together, the findings of these two studies indicate that fibrocytes contribute to the lesional fibroblast population present in 
different forms of scars, particularly in post-burn hypertrophic scars, and confirm the in vivo evidence from animal studies $^{6,11}$ that fibrocytes downregulate CD34 expression as they differentiate into mature mesenchymal cells, synthesizing higher levels of collagens.

\section{Airway Remodeling in Asthma}

Asthma is a common ${ }^{58}$ and heterogeneous ${ }^{59}$ inflammatory disorder of the airways, which usually shows a chronically relapsing course. Recurrent episodes of wheezing and shortness of breath manifest in concomitance with a worsening of the inflammatory infiltrate in the airways, and an abnormal broncho-constrictive response on exposure to a variety of environmental agents persists in the remission phases. In most forms of asthma, the bronchial mucosa of patients shows structural and functional abnormalities of the bronchial epithelium, an inflammatory infiltrate mainly composed of activated $\mathrm{T}$ lymphocytes, $\mathrm{CD}^{+} 4^{+}$monocytes, eosinophils and mast cells, and remodeling of the airway tissue architecture. ${ }^{60-66}$ Peculiar aspects of the remodeling process include angiogenesis, the accumulation of fibroblasts and myofibroblasts below the epithelial basement membrane, thickening of the lamina reticularis as a result of an excessive deposition of ECM molecules and bronchial smooth muscle cells hyperplasia. ${ }^{65-70}$ Repeated cycles of airway inflammation and repair with unsuccessful healing are thought to represent the driving force for most of these structural alterations, ${ }^{66}$ as the bronchial mucosa of asthmatic patients resembles a wounded tissue where neither the inflammatory phase nor the reparative phase resolves completely. ${ }^{19}$ The remodeling process ultimately leads to thickening of the airway wall and may cause the irreversible decline in lung function that can be observed in many patients with long-standing disease. ${ }^{68-70}$

In the allergic form of asthma, every exposure to the allergens to which the patients are sensitized triggers an increased productions of chemokines and growth factors, including the CCR2 ligand monocyte chemoattractant protein-1 (MCP-1), ET-1 and TGF- $\beta_{1}$, and further recruitment of $\mathrm{CD}_{14}{ }^{+}$monocytes, $\mathrm{T}$ helper (Th)2 lymphocytes and eosinophils into the bronchial mucosa. ${ }^{62,64,71-74}$ The inflammatory infiltrate is particularly abundant in the subepithelial area because epithelial cells are a major source of chemokines and growth factors. ${ }^{19,62,72}$ It persists for days ${ }^{73,74}$ and is associated with the emergence of new myofibroblasts below the epithelial basement membrane within $24 \mathrm{~h}$ after allergen exposure. ${ }^{75}$ One study from our group ${ }^{11}$ demonstrated the appearance of fibrocytes, expressing CD34 in conjunction with pro-collagen I mRNA, in the airways of patients with allergic asthma between 4 and $24 \mathrm{~h}$ after the inhalation of the clinically relevant allergen. Within $24 \mathrm{~h}$ following allergen inhalation, a substantial proportion of the $\mathrm{CD} 4^{+}$pro-collagen I $\mathrm{mRNA}^{+}$cells also expressed $\alpha$-SMA and localized to areas of new ECM deposition below the epithelial basement membrane. ${ }^{11}$ As reviewed elsewhere, ${ }^{72}$ the allergen-induced accumulation of fibrocytes in the bronchial mucosa of these patients is usually preceded by a worsening of the inflammatory infiltrate and is paralleled by an increased production of ET-1 from epithelial cells and endothelial cells and increased release of the biologically active form of TGF- $\beta_{1}$ from epithelial cells and eosinophils. The presence of activated $\mathrm{T}$ lymphocytes and the high levels of TGF- $\beta_{1}$ at the tissue site may promote the differentiation of fibrocytes from the $\mathrm{CD} 14^{+}$monocytes recruited at an earlier stage, as a result of the increased production of MCP-1. Moreover, the peak increase in the release of ET-1 and TGF$\beta_{1}$ in the bronchial mucosa is observed at $24 \mathrm{~h}$ following allergen inhalation, and may favor further differentiation of fibrocytes into new myofibroblasts at this stage. ${ }^{11,72}$ Other cytokines produced by inflammatory cells ${ }^{64,66}$ may also contribute to promote the development of fibrocytes from their precursors (Th2 cell-derived IL-4 and IL-13) and induce fibrocyte proliferation (monocyte/macrophage- and dendritic cell-derived IL-1 $\beta$ ).

Additional information on the role of fibrocytes in allergic asthma has been provided by other investigators ${ }^{15}$ who detected $\mathrm{CD} 34^{+} \mathrm{CD} 45^{+} \alpha-\mathrm{SMA}^{+}$cells in bronchial biopsies from untreated patients with mild disease. These fibrocytes differentiating into myofibroblasts appeared in clusters close to the epithelial basement membrane and their density correlated with the thickness of the lamina reticularis. Moreover, similar cells spontaneously emerged in cultures of bronchoalveolar mononuclear cells from asthmatic patients, suggesting that there were fibrocyte precursors in the inflammatory infiltrate. The correlation between the number of $\alpha$-SMA ${ }^{+}$fibrocytes and the thickness of the lamina reticularis supports the hypothesis that fibrocyte-derived lesional myofibroblasts contribute to the deposition of new ECM molecules below the epithelium in asthma. In a more recent study, Kaur et $a^{16}$ demonstrated the expression of CCR7 in the myofibroblasts and other mesenchymal cells present in the bronchial mucosa of patients with asthma of various severities, confirming their possible origin from fibrocytes and their circulating precursors. These investigators also observed an increased production of the CCR7 ligand CCL19 by endothelial cells, mast cells and smooth muscle cells in asthmatic airways, suggesting that the CCL19/CCR7 axis may play an important role in the recruitment of mesenchymal precursors in asthma.

The accumulation of fibrocytes below the epithelial basement membrane in asthmatic airways may cause beneficial as well as detrimental effects. Although the excessive deposition of ECM molecules in the lamina reticularis by fibrocyte-derived myofibroblasts increases the thickness of the airway wall, both the fibrotic process and the contractile force generated by myofibroblasts may enhance the resistance to mechanical stress of a bronchial wall weakened by the inflammatory process, thereby preventing further damage, especially during broncho-constrictive episodes. On the other hand, fibrocyte produce basement membrane-degrading enzymes, such as MMP-9, and pro-angiogenic factors that 
facilitate normal wound healings, ${ }^{37}$ but may have a deleterious effect in a wounded tissue where neither the inflammatory phase nor the reparative phase resolves completely. ${ }^{19}$ Moreover, fibrocytes may be involved in the capture of the antigens that cross the epithelial barrier and present them to lamina propria $\mathrm{CD}^{+}{ }^{+}$and $\mathrm{CD}^{+}{ }^{+} \mathrm{T}$ lymphocytes. ${ }^{34,35}$ Therefore, these cells may work in concert with dendritic cells to amplify the allergic inflammatory reaction after every exposure to the relevant allergens. ${ }^{64,66}$

\section{Interstitial Pulmonary Fibroses}

Idiopathic interstitial pneumonias are a heterogeneous group of rare chronic pulmonary diseases of unknown etiology that are characterized by varying degrees of inflammation and interstitial pulmonary fibrosis. ${ }^{76}$ Idiopathic pulmonary fibrosis/usual interstitial pneumonia is the most common form. ${ }^{76}$ This disease is unresponsive to currently available therapeutic options and frequently leads to death within 5 years from the time it has been diagnosed. ${ }^{77-79}$ The chronic fibro-proliferative process is limited to the lung and is characterized by the presence of clusters of fibroblasts and myofibroblasts demarcated from surrounding cells (fibroblastic foci), which indicates active fibrogenesis. ${ }^{80,81}$ Myofibroblast are considered the dominant source of interstitial collagens and their persistence at the sites of active fibrogenesis is associated with poor prognosis, leading to progressive tissue remodeling, consequent loss of lung function and fatal outcome. ${ }^{80,81}$

Two groups ${ }^{82,83}$ have evaluated the possibility that fibrocytes are involved in the pathogenesis of idiopathic interstitial pneumonias. One study ${ }^{82}$ was conducted in patients with idiopathic pulmonary fibrosis/usual interstitial pneumonia, nonspecific interstitial pneumonia and respiratory bronchiolitis-associated interstitial lung disease and demonstrated the presence of cells coexpressing CCR7 and CD45 predominantly in the lung tissue specimens from patients with idiopathic pulmonary fibrosis/usual interstitial pneumonia. These cells did not express CD34 or $\alpha$-SMA and they did not emerge specifically in areas of active collagen deposition. A diffuse pattern of CXCR4 expression was seen in all tissue specimens and most of the CXCR ${ }^{+}$cells appeared to be infiltrating mononuclear cells. In the second study, ${ }^{83}$ lung tissue bioptic specimens from patients with idiopathic pulmonary fibrosis/usual interstitial pneumonia and nonspecific interstitial pneumonia where compared with normal surgical tissue specimens. Increased expression of the CXCR4 ligand CXCL12 was observed in both fibrotic diseases. The investigators did not examine the lung tissue specimens for the presence of fibrocytes. However, they observed peripheral blood monocytosis in the patients with lung fibrotic diseases and could isolate higher number of CXCR4 ${ }^{+}$ $\mathrm{CD}_{4} 5^{+}$collagen $\mathrm{I}^{+}$fibrocytes from the peripheral blood mononuclear cells of these patients than from the peripheral blood mononuclear cells of normal donors. Although the latter data suggest increased release of $\mathrm{CXCR} 4^{+} \mathrm{CD} 45^{+}$ mesenchymal precursors from the bone marrow in patients with some forms of idiopathic interstitial pneumonias, there is at present no direct in vivo evidence of an increased accumulation of fibrocytes in the lungs of these patients. In vitro experiments ${ }^{84}$ have demonstrated the expression of functional CCR7 on fibroblasts isolated from the lungs of patients with idiopathic pulmonary fibrosis/usual interstitial pneumonia, but these cells do not seem to show the phenotypic characteristics of fibrocytes, being $\mathrm{CD} 34^{-} \mathrm{CD} 45^{-}$ $\mathrm{CD}^{-} 6^{-}$cells. Moreover, normal fibroblasts also appear to contain CCR7 transcripts. ${ }^{84}$

\section{Systemic Fibroses}

Nephrogenic systemic fibrosis (also known as nephrogenic fibrosing dermopathy) is a disease that occurs almost exclusively in patients with renal dysfunction, particularly in those undergoing hemodialysis for end-stage renal disease. ${ }^{8-87}$ The clinical course of the fibrotic disease is characterized by a symmetric and progressive hardening of the skin, which most commonly affects the extremities. ${ }^{85,87}$ Involvement of multiple organs, including heart, lungs, skeletal muscles and diaphragm, has been reported in many patients and the fibrotic process can ultimately lead to death. ${ }^{85-87}$ The pathogenesis of this condition is unclear, but it has been recently associated with the use of gadolinium-containing contrast agents for magnetic resonance imaging. ${ }^{86,87}$ It has been proposed that the fibrotic lesions in the skin and in various organs may develop as a consequence of the deposition of the toxic gadolinium ions in the tissues of certain individuals with advanced renal disease, ${ }^{86,87}$ because they have metabolic acidosis or other conditions that favor the liberation of these ions. ${ }^{86}$ The lesional skin and affected organs show a fibroproliferative process and a dense infiltrate, mainly composed of CD $68^{+}$monocytes and abundant spindle-shaped cells that are immersed in a network of elastic fibers and collagen. ${ }^{88-91}$ The accumulation of $\mathrm{CD} 8^{+}$monocytes at the tissue sites is a constant finding in early disease. ${ }^{88,90}$ Interstitial and vascular calcium deposits have been described in several affected tissues and may represent deposits of gadolinium with calcium phosphates ${ }^{87} \mathrm{~A}$ pronounced increase in the thickness of the adventitial layer of small- and medium-size arterioles in the lungs and perivascular fibrosis in the small coronary arterioles in the heart have also been reported ${ }^{91}$ and may result from gadolinium-induced endothelial damage, as suggested by animal studies. ${ }^{92}$ The expression of CD34 and/ or CD45 on lesional spindle cells has been detected in various studies, ${ }^{14,88,89,91}$ one of which has unequivocally demonstrated that these cells are actually fibrocytes by double staining for CD45 and pro-collagen I. ${ }^{14}$ In the involved tissues, such cells appear at an early stage of the fibrotic process $^{91}$ and localize to areas of active fibrogenesis. ${ }^{14,89,91}$ Because high levels of TGF- $\beta_{1}$ mRNA have been observed in the lesional skin and affected muscles, ${ }^{90}$ this growth factor may play a major role in the local differentiation of fibrocytes from the precursors of the monocyte lineage. 
It has been proposed that fibrocytes may also been involved in the pathogenesis of systemic sclerosis. ${ }^{93}$ This connective tissue disease of unknown etiology is characterized by autoantibody production, microvascular stenosis and excessive deposition of collagen in the skin (scleroderma) and in various organs, particularly in the lungs. ${ }^{94-96}$ Endothelial damage and perivascular cellular infiltrates, with numerous $\mathrm{T}$ lymphocytes and monocytes, have been observed at an early stage of the pathologic conditions, ${ }^{97,98}$ before microscopic evidence of fibrosis. Myofibroblasts are the dominant source of ECM molecules during the fibroproliferative process. ${ }^{99}$ Increased expression of MCP-1, TGF- $\beta_{1}$ and ET- 1 has been demonstrated in the skin and in the lungs of affected individuals. ${ }^{95,100-103}$ Notably, unlike classical monocytes and macrophages, ${ }^{42}$ alveolar monocytes/macrophages of patients with systemic sclerosis and associated interstitial pulmonary fibrosis spontaneously release high amounts of fibronectin, ${ }^{104}$ and lesional fibroblasts in the skin of individuals with systemic sclerosis aberrantly express one of the markers of the $\mathrm{CD} 14^{+} \mathrm{CD}^{-} 6^{-}$subset of mononuclear cells from which fibrocytes likely originate, ${ }^{38,39}$ the MCP-1 receptor CCR2. ${ }^{105}$ Furthermore, numerous cells synthesizing new collagen and expressing factor XIIIa, a marker of cells of the monocyte lineage, ${ }^{106}$ have been detected in the lesional skin of individuals with scleroderma. ${ }^{107}$ Differing from the spindleshaped cells present in low number in the clinically uninvolved skin, these fibroblasts do not appear to express CD34. ${ }^{107}$ Taken together, these observations suggest that an increased, MCP-1-mediated, recruitment of precursors of the monocyte lineage may occur in the skin and in the lungs of patients with systemic sclerosis, possibly as a consequence of an initial endothelial damage ${ }^{38,39,108}$ or the ischemic insults resulting from multiple microvascular obstructions. ${ }^{108}$ The maturation of fibrocytes from these precursors at the tissue sites may be favored by the increased levels of TGF- $\beta_{1}$ and ET-1 in the micro-environment and the differentiation of fibrocytes into mature collagen-producing cells may be associated with a downregulation of CD34 expression, as it happens in cultured fibrocytes ${ }^{6,11,17,19,21}$ or in labeled fibrocytes that have migrated to the sites of ongoing tissue fibrogenesis. ${ }^{11}$ Interestingly, patients suffering from systemic sclerosis have low serum and tissue levels of SAP in comparison with healthy individuals, ${ }^{5}$ and this alteration may contribute to an uncontrolled differentiation of fibrocytes in the skin and in organs involved by the disease.

\section{Atherosclerosis}

Atherosclerosis is an inflammatory disease that mostly involves the regions of large- and medium-sized arteries exposed to mechanical stress. ${ }^{109,110}$ Initial lesions are characterized by endothelial damage and accumulation of lipoproteins in the subendothelial space. ${ }^{109,111}$ Monocytes are then recruited into the subendothelial area, where they engulf modified lipids and become foam cells. ${ }^{111}$ These cells, T lymphocytes and a few myofibroblasts form a fatty streak. ${ }^{111}$
The subsequent accumulation of extracellular lipids leads to the formation of the fatty core of the atheroma in the intima. ${ }^{112,113}$ The intimal area overlaying the core contains foam cells and isolated myofibroblasts synthesizing new collagen. ${ }^{113,114}$ Further progression of the atherosclerotic lesions is characterized by the development of a fibrous cap (known as fibro-atheroma), with increased numbers of myofibroblasts and excessive deposition of collagen and other ECM molecules. ${ }^{113,114}$ The remodeling process may be either expansive or constrictive in nature, and in both cases, causes luminal narrowing with consequent tissue ischemia. ${ }^{115}$ It is considered to represent the intimal response to continual injury, with failure to resolve the chronic inflammatory infiltrate, like the remodeling process that occurs in chronic wounds ${ }^{116-118}$ and in the bronchial mucosa of asthmatic patients. ${ }^{19}$

Fibrocytes coexpressing pro-collagen I and CD34 have been recently identified in the fibrous cap of human atherosclerotic lesions. ${ }^{17,118}$ Moreover, subendothelial myofibroblasts expressing the monocyte marker CD $68^{119}$ or CD $34^{118}$ have been found in lipid-rich areas of the atherosclerotic intima in human aorta ${ }^{119}$ and in the fibrous cap of human carotid arteries, ${ }^{118}$ suggesting that these cells originate from fibrocytes. Notably, one of the subsets of monocytes that are preferentially recruited into the arterial wall during experimentally induced atherosclerosis in mice ${ }^{120}$ represents the murine counterpart of the human inflammatory subset of $\mathrm{CD}_{1} 4^{+} \mathrm{CD} 16^{-}$mononuclear cells, expressing the MCP- 1 receptor CCR2. ${ }^{38,39}$ Thus, the CD14 ${ }^{+}$ $\mathrm{CD} 6^{-}$CCR2 ${ }^{+}$subpopulation may be involved in human atherogenesis and may contain fibrocyte precursors that contribute to the development of advanced atherosclerotic lesions. This hypothesis would be supported by data from epidemiologic studies ${ }^{121,122}$ that have suggested a major role of MCP-1 in the pathogenesis of atherosclerosis and disease progression.

It is noteworthy that the clinical significance of an atherosclerotic lesion is largely dependent on its composition, ${ }^{123}$ which is critically determined by the balance between inflammation and fibrosis ${ }^{124}$ and affects the stability of the plaque. Plaques with a thick fibrous cap and a small fatty core are reasonably stable, whereas plaques having a large fat core and thin fibrous cap are unstable ${ }^{123}$ and can easily rupture, exposing or releasing the highly thrombogenic content of the core. ${ }^{118}$ Thus, the accumulation of fibrocytes in the fibrous cap of the atherosclerotic lesion may have a beneficial effect in stabilizing the plaque that outweighs the detrimental increase in plaque volume. ${ }^{118}$ Because fibrocytes seem to derive from the immature population of bone marrow-derived precursors of the monocyte lineage ${ }^{5,9,10}$ from which foam cells also originate, ${ }^{120}$ the preferential differentiation of these precursors into fibrocytes rather than inflammatory monocytes and foam cells might at the same time stabilize the plaque through the formation of the fibrous cap and limit the expansion of the fatty core, as recently proposed. ${ }^{118}$ Athero- 
sclerotic lesions are known to contain high levels of TGF- $\beta_{1}{ }^{123}$ and ET- $1,{ }^{108}$ and both these pro-fibrotic factors may play a key role in promoting the differentiation of fibrocytes into myofibroblasts, thereby favoring the development of the fibrous cap.

\section{Reactive Fibrosis in Chronic Pancreatitis and Cystitis}

Stromal cells expressing CD34 have been found in tissue specimens from patients with chronic pancreatitis ${ }^{13,29}$ and chronic cystitis. ${ }^{24}$ In chronic pancreatitis, the accumulation of CD34 ${ }^{+}$fibrocyte-like cells appears to be associated with a parallel increase in the number of $\alpha$-SMA myofibroblasts and these alterations are not observed in the normal pancreatic stroma. ${ }^{13}$ The phenotype of the CD34-positive stromal cells and their relative contribution to the population of lesional myofibroblasts in these pathologic conditions remain to be elucidated.

\section{Tumor-Induced Stromal Reaction}

Immature monocytes released from the bone marrow are actively recruited into solid tumors from the local circulation and represent a prominent component of the leukocyte infiltrate, particularly in malignant lesions. ${ }^{108}$ In mice, the mesenchymal cells that contribute to the development of tumor stroma also appear to originate, at least in part, from bone marrow-derived precursors. ${ }^{50,125,126}$ Several studies have demonstrated the presence of CD34-positive, fibrocytelike stromal cells in various human benign and invasive tumors. ${ }^{13,24-32}$ In general, analysis of cells single stained for CD34 or $\alpha$-SMA on serial tissue sections has indicated that $\mathrm{CD}_{3}{ }^{+} \alpha-\mathrm{SMA}^{-}$fibroblasts are usually found in the stroma encapsulating benign tumors, whereas $\mathrm{CD}^{-} 4^{-} \alpha-\mathrm{SMA}^{+}$ stromal cells are particularly frequent around invasive carcinoma. Because fibrocytes exhibit antigen-presenting activity $^{34}$ and activate cytotoxic T lymphocytes, ${ }^{35}$ the apparent selective loss of the stromal network of $\mathrm{CD}_{3}{ }^{+}$fibrocyte-like

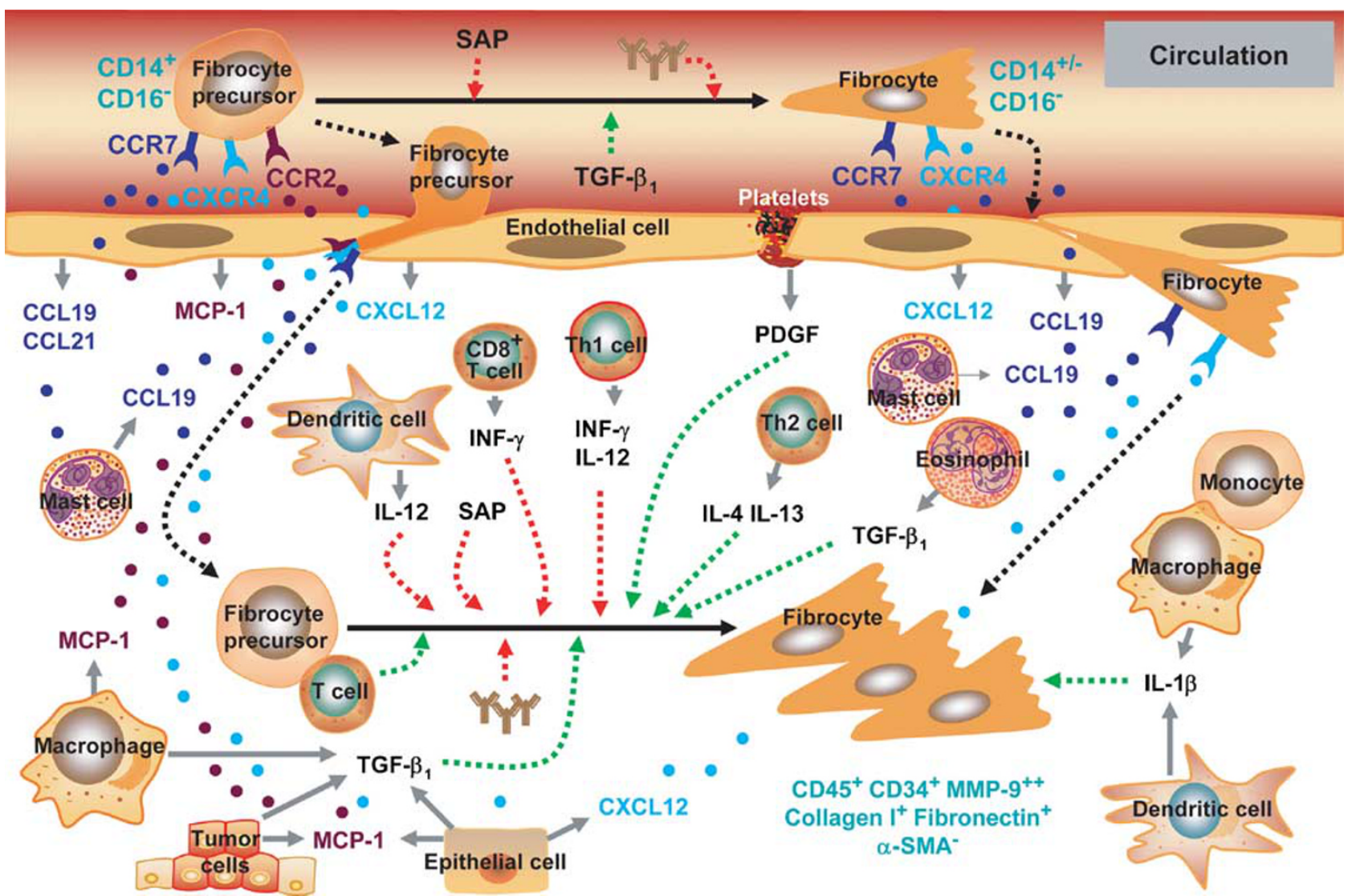

Figure 1 Signals that may promote (dashed green arrows) ${ }^{3,12,23,48}$ or inhibit (dashed red arrows) s, $, 10,48$ the accumulation of fibrocytes during human reparative or reactive fibroses. The possible cell sources of cytokines, growth factors and chemokines (gray arrows) derive from published studies ${ }^{16,63,64}$ or reviews. ${ }^{19,38,39,49,62,65,66,72,108,118,128}$ The maturation of fibrocytes from their bone marrow-derived precursors (solid black arrows) may predominantly occur at tissue sites rather than in the circulation, because SAP is a constitutive serum protein that may inhibit the maturation process. ${ }^{5,9,10,48}$ MCP-1, CXCL12 and the ligands of CCR7, CCL19 and CCL21 may all contribute to various extents to the recruitment of fibrocyte precursors into tissue sites (dashed black arrows), depending on the pathological condition and the nature of the inflammatory infiltrate. However, in disorders associated with low serum levels of SAP, such as systemic sclerosis, ${ }^{5}$ or with high circulating levels of TGF- $\beta_{1}$, such as extensive burn injuries, ${ }^{4}$ there may be appreciable numbers of fibrocytes in the peripheral blood and these cells may be directly recruited into lesional areas through CXCR4- or CCR7-mediated pathways (dashed black arrows). (Designed with the use of the ScienceSlides 2005 software, VisiScience Corporation, Chapel Hill, NC, USA). 
cells in invasive carcinomas ${ }^{24,30}$ might reflect the fact that these tumors have escaped from host immune surveillance. However, both cancerous cells and the cells at the interface of malignant lesions produce high amounts of TGF- $\beta_{1}{ }^{32,127}$ and hypoxic regions of tumors contain elevated levels of ET- $1 .{ }^{108}$ Therefore, the apparent loss of $\mathrm{CD} 34^{+}$fibrocyte-like cells and the concomitant increase in the number of $\alpha$-SMA ${ }^{+}$ $\mathrm{CD} 34^{-}$cells in the stroma surrounding malignant lesions $^{24,28,30}$ may alternatively reflect an increased differentiation of $\mathrm{CD}_{3} 4^{+}$fibrocytes into mature $\mathrm{CD} 34^{-}$ myofibroblasts triggered by the presence of excessive levels of TGF- $\beta_{1}$ and ET- 1 in the micro-environment. The pro-angiogenic activity of fibrocytes ${ }^{37}$ also suggests that these cells may potentially contribute to the metastatic progression of invasive tumors. ${ }^{108}$ Interestingly, $\mathrm{CD} 45^{+} \mathrm{CD} 34^{-} \alpha-\mathrm{SMA}^{+}$ cells of bone marrow origin have been identified as an important component of cancer-induced stroma in the advanced stage of development of an implanted large-cell neuroendocrine carcinoma in bone marrow chimeric mice ${ }^{50}$ and such cells show the phenotype of fibrocytes undergoing further differentiation into mature myofibroblasts.

\section{CONCLUDING REMARKS AND PERSPECTIVES}

A growing body of literature over the last decade has revealed that human fibrocytes may serve as an important source of fibroblasts and myofibroblasts during normal or aberrant reparative processes and in fibrotic disorders or stromal reactions, predominantly associated with a persistent inflammatory infiltrate or with the selective recruitment of monocytes induced by ischemic changes and tumor development. Some of the micro-environmental signals that may promote or inhibit the maturation of fibrocytes and their differentiation into lesional fibroblasts and myofibroblasts in those conditions have been defined, with the support of in vitro studies and in vivo experiments in various animal models of reactive or reparative tissue fibrosis and vascular remodeling (Figures 1 and 2). Further investigations in this area can help identify fibrocyte-specific signaling pathways that may serve as new therapeutic targets. For example, prevention of detrimental tissue or vascular remodeling and metastatic progression of invasive tumors may be achieved by facilitating or inhibiting the maturation of fibrocytes or their differentiation into mature mesenchymal cells at tissue sites.

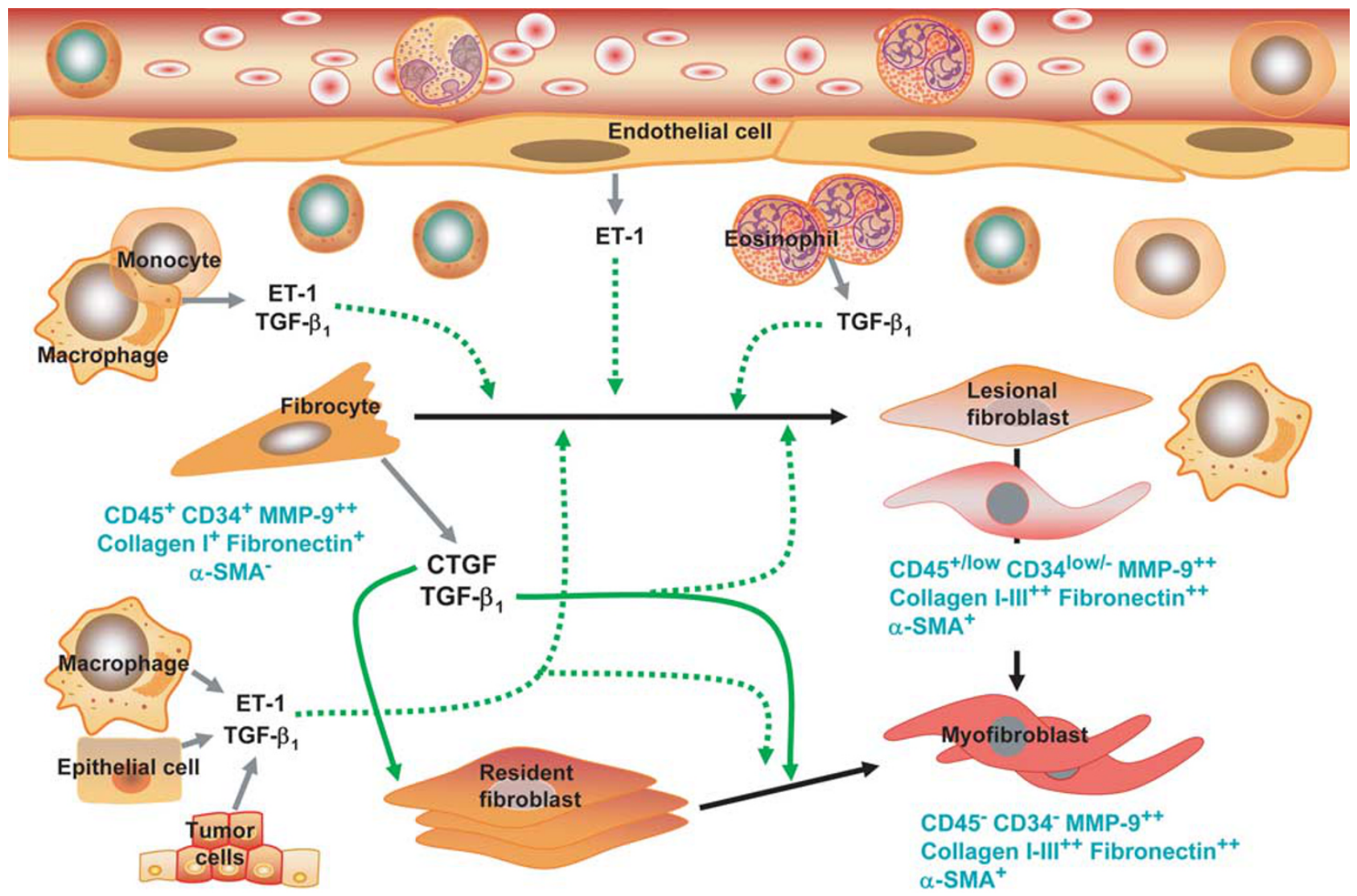

Figure 2 Signals that may promote (dashed green arrows) ${ }^{3,11,12,23,48}$ the differentiation of fibrocytes into lesional fibroblasts and myofibroblasts (solid black arrows) during human reparative or reactive fibroses. The possible cell sources of ET-1 and TGF- $\beta_{1}$ (gray arrows) are derived from published studies ${ }^{11,103}$ or reviews. ${ }^{19,49,65,66,72,108,118}$ Fibrocytes themselves release growth factors, such as connective tissue growth factor (CTGF) and TGF- $\beta_{1}{ }^{2,36}$ which may induce the proliferation of resident fibroblasts and promote their differentiation into myofibroblasts in concert with the ET- 1 and TGF- $\beta_{1}$ produced by other cell types (solid green arrows). The differentiation of fibrocytes into mature myofibroblasts is associated with the loss of surface markers that are currently used to distinguish fibrocytes and fibrocyte-derived cell from the myofibroblasts originating as a result of the activation of resident fibroblasts. ${ }^{6,11}$ (Designed with the use of the ScienceSlides 2005 software, VisiScience Corporation, Chapel Hill, NC, USA.) 
Moreover, fibrocytes can be easily developed from circulating $\mathrm{CD}_{14}{ }^{+}$mononuclear cells and expanded ex vivo. Given the propensity of intravenously injected fibrocytes to migrate into inflamed tissues, ${ }^{3,11}$ expanded autologous cells could be used to deliver therapeutic gene constructs to improve ineffective repair processes and to encapsulate cancerous cells or cause their death.

\section{DUALITY OF INTEREST}

The authors have no duality of interest to declare.

1. Bucala R, Spiegel LA, Chesney J, et al. Circulating fibrocytes define a new leukocyte subpopulation that mediates tissue repair. Mol Med 1994;1:71-81.

2. Chesney J, Metz C, Stavitsky AB, et al. Regulated production of type I collagen and inflammatory cytokines by peripheral blood fibrocytes. J Immunol 1998;160:419-425.

3. Abe R, Donnelly SC, Peng $T$, et al. Peripheral blood fibrocytes: differentiation pathway and migration to wound sites. J Immunol 2001;166:7556-7562.

4. Yang L, Scott PG, Giuffre J, et al. Peripheral blood fibrocytes from burn patients: identification and quantification of fibrocytes in adherent cells cultured from peripheral blood mononuclear cells. Lab Invest 2002;82:1183-1192.

5. Pilling $D$, Buckley $C D$, Salmon $M$, et al. Inhibition of fibrocyte differentiation by serum amyloid P. J Immunol 2003;171:5537-5546.

6. Mori L, Bellini A, Stacey MA, et al. Fibrocytes contribute to the myofibroblast population in wounded skin and originate from the bone marrow. Exp Cell Res 2005;304:81-90.

7. Ebihara $Y$, Masuya M, Larue AC, et al. Hematopoietic origins of fibroblasts: II. In vitro studies of fibroblasts, CFU-F and fibrocytes. Exp Hematol 2006;34:219-229.

8. Kisseleva $\mathrm{T}$, Uchinami $\mathrm{H}$, Feirt $\mathrm{N}$, et al. Bone-marrow derived fibrocytes participate in pathogenesis of liver fibrosis. J Hepatol 2006;45:429-438.

9. Haudek SB, Xia Y, Huebener $\mathrm{P}$, et al. Bone marrow-derived fibroblast precursors mediate ischemic cardiomyopathy in mice. Proc Natl Acad Sci USA 2006;103:18284-18289.

10. Pilling D, Tucker NM, Gomer RH. Aggregated IgG inhibits the differentiation of human fibrocytes. J Leukoc Biol 2006;79:1242-1251.

11. Schmidt M, Sun G, Stacey MA, et al. Identification of circulating fibrocytes as precursors of bronchial myofibroblasts in asthma. $J$ Immunol 2003;171:380-389.

12. Yang $L$, Scott PG, Dodd C, et al. Identification of fibrocytes in postburn hypertrophic scar. Wound Repair Regen 2005;13:2215-2224.

13. Barth PJ, Ebrahimsade $S$, Hellinger A, et al. CD34 ${ }^{+}$fibrocytes in neoplastic and inflammatory pancreatic lesions. Virchows Arch 2002;440:128-133.

14. Cowper SE, Bucala R. Nephrogenic fibrosing dermopathy: suspect identified, motive unclear. Am J Dermatopathol 2003;25:358.

15. Nihlberg K, Larsen K, Hultgardh-Nilsson A, et al. Tissue fibrocytes in patients with mild asthma: a possible link to thickness of reticular basement membrane? Respir Res 2006;7:50 (doi:10.1186/1465-99217-50).

16. Kaur $D$, Saunders $R$, Berger $P$, et al. Airway smooth muscle and mast cell-derived CC chemokine ligand 19 mediate airway smooth muscle migration in asthma. Am J Respir Crit Care Med 2006;174:1179-1188.

17. Phillips RJ, Burdick MD, Hong K, et al. Circulating fibrocytes traffic to the lungs in response to CXCL12 and mediate fibrosis. J Clin Invest 2004;114:438-446.

18. Moore BB, Kolodsick JE, Thannickal VJ, et al. CCR2-mediated recruitment of fibrocytes to the alveolar space after fibrotic injury. Am J Pathol 2005;166:675-684.

19. Mattoli S. Tissue repair in asthma: the origin of airway subepithelial fibroblasts and myofibroblasts. In: Chaponnier C, Desmoulière A, Gabbiani G (eds). Tissue Repair, Contraction and the Myofibroblast, Chapter 4. Landes Bioscience and Springer Science, Business Media: Georgetown, TX, 2006, pp 40-46.

20. Frid MG, Brunetti JA, Burke DL, et al. Hypoxia-induced pulmonary vascular remodeling requires recruitment of circulating mesenchymal precursors of a monocyte/macrophage lineage. Am J Pathol 2006;168:659-669.

21. Moore BB, Murray L, Das A, et al. The role of CCL12 in the recruitment of fibrocytes and lung fibrosis. Am J Respir Cell Mol Biol 2006;35: 175-181.

22. Sakai N, Wada T, Yokoyama $\mathrm{H}$, et al. Secondary lymphoid tissue chemokine (SLC/CCL21)/CCR7 signaling regulates fibrocytes in renal fibrosis. Proc Natl Acad Sci USA 2006;103:14098-14103.

23. Varcoe RL, Mikhail M, Guiffre AK, et al. The role of the fibrocyte in intimal hyperplasia. J Thromb Haemost 2006;4:1125-1133.

24. Nimphius $W$, Moll R, Olbert $P$, et al. CD34 fibrocytes in chronic cystitis and noninvasive and invasive urothelial carcinomas of the urinary bladder. Wirchows Archiv 2007;450:179-185.

25. Barth PJ, Ramaswamy A, Moll R. CD34(+) fibrocytes in normal cervical stroma, cervical intraepithelial neoplasia III, and invasive squamous cell carcinoma of the cervix uteri. Virchows Arch 2002;441:564-568.

26. Barth PJ, Ebrahimsade $S$, Ramaswamy $A$, et al. CD34 ${ }^{+}$fibrocytes in invasive ductal carcinoma, ductal carcinoma in situ and benign breast lesions. Virchows Arch 2002;440:298-303.

27. Ramaswamy A, Moll R, Barth PJ. CD34(+) fibrocytes in tubular carcinomas and radial scars of the breast. Virchows Arch 2003;443: 536-540.

28. Chauhan $\mathrm{H}$, Abraham A, Phillips JRA, et al. There is more than one kind of myofibroblast: analysis of CD34 expression in benign, in situ, and invasive breast cancer. J Clin Pathol 2003;56:271-276.

29. Kuroda N, Toi M, Nakayama $\mathrm{H}$, et al. The distribution and role of myofibroblasts and CD34-positive stromal cells in normal pancreas and various pancreatic lesions. Histol Histopathol 2004;19:59-67.

30. Barth PJ, Schenck zu Schweinsberg T, Ramaswamy A, et al. CD34 ${ }^{+}$ fibrocytes, alpha-smooth muscle antigen-positive myofibroblasts, and CD117 expression in the stroma of invasive squamous cell carcinomas of the oral cavity, pharynx, and larynx. Virchows Arch 2004;444:231-234.

31. Yazhou C, Wenlv S, Weidong Z, et al. Clinicopathological significance of stromal myofibroblasts in invasive ductal carcinoma of the breast. Tumour Biol 2004;25:290-295.

32. Kojc N, Zidar N, Vodopivec B, et al. Expression of CD34, alpha-smooth muscle actin, and transforming growth factor beta1 in squamous intraepithelial lesions and squamous cell carcinoma of the larynx and hypopharynx. Human Pathol 2005;36:16-21.

33. Hong KM, Burdick MD, Phillips RJ, et al. Characterization of human fibrocytes as circulating adipocyte progenitors and the formation of human adipose tissue in SCID mice. FASEB J 2005;19:2029-2031.

34. Chesney J, Bacher M, Bender A, et al. The peripheral blood fibrocyte is a potent antigen-presenting cell capable of priming naïve T cells in situ. Proc Natl Acad Sci USA 1997;94:6307-6312.

35. Balmelli C, Ruggli N, McCullough K, et al. Fibrocytes are potent stimulators of anti-virus cytotoxic T cells. J Leukoc Biol 2005;77: 923-933.

36. Wang J, Jiao $\mathrm{H}$, Stewart $\mathrm{T}$, et al. Fibrocytes from burn patients regulate the activities of fibroblasts. Wound Repair Regen 2007;15:113-121.

37. Hartlapp I, Abe R, Saeed RW, et al. Fibrocytes induce an angiogenic phenotype in cultured endothelial cells and promote angiogenesis in vivo. FASEB J 2001;15:2215-2224.

38. Gordon S, Taylor PR. Monocyte and macrophage heterogeneity. Nature Rev Immunol 2005:5:953-964.

39. Tacke F, Randolph GJ. Migratory fate and differentiation of blood monocyte subsets. Immunobiology 2006;211:609-618.

40. Sunderkotter C, Nikolic T, Dillon MJ, et al. Subpopulations of mouse blood monocytes differ in maturation stage and inflammatory response. J Immunol 2004;172:4410-4417.

41. Zhao Y, Glesne D, Huberman E. A human peripheral blood monocytederived subset acts as pluripotent stem cells. Proc Natl Acad Sci USA 2003;100:2426-2431.

42. Kuwana $\mathrm{M}$, Okazaki $\mathrm{Y}$, Kodama $\mathrm{H}$, et al. Human circulating $\mathrm{CD} 14^{+}$ monocytes as a source of progenitors that exhibit mesenchymal cell differentiation. J Leukoc Biol 2003;74:833-845.

43. Kim $\mathrm{CH}$, Pelus $\mathrm{LM}$, White JR, et al. Macrophage-inflammatory protein$3 \boldsymbol{\beta} /$ EB11-ligand chemokine/CK $\boldsymbol{\beta}$-11, a CC chemokine, is a chemoattractant with a specificity for macrophage progenitors among myeloid progenitor cells. J Immunol 1998;161:2580-2585

44. Kim CH, Broxmeyer HE. SLC/exodus/6Ckine/TCA4 induces chemotaxis of hematopoietic progenitor cells: differential activity of ligands of 
CCR7, CXCR3, or CXCR4 in chemotaxis vs suppression of progenitor proliferation. J Leukoc Biol 1999;66:455-461.

45. He Q, Wan C, Li G. Concise review: multipotent mesenchymal stromal cells in blood. Stem Cells 2007;25:69-77.

46. Hennrick KT, Keeton AG, Nanua $S$, et al. Lung cells from neonates show a mesenchymal stem cell phenotype. Am J Respir Crit Care Med 2007:175:1158-1164.

47. Deschaseaux F, Gindraux F, Saadi $R$, et al. Direct selection of human bone marrow mesenchymal stem cells using an anti-CD49a antibody reveals their CD45 ${ }^{\text {med,low }}$ phenotype. Br J Haematol 2003;122:506-517.

48. Pilling $\mathrm{D}$, Gomer RH. Regulatory pathways for fibrocyte differentiation. Chapter 3. In: Bucala R (ed). Fibrocytes: New Insights Into Tissue Repair and Systemic Fibroses. World Scientific Publishing Co. Pte. Ltd.: Singapore, 2007, pp 37-60.

49. Werner S, Grose R. Regulation of wound healing by growth factors and cytokines. Physiol Rev 2003;83:835-870.

50. Ishii G, Sangai T, Sugiyama K, et al. In vivo characterization of bone marrow-derived fibroblasts recruited into fibrotic lesions. Stem Cells 2005;23:699-706.

51. Ishida Y, Kimura A, Kondo T, et al. Essential roles of the CC chemokine ligand 3-CC chemokine receptor 5 axis in bleomycin-induced pulmonary fibrosis through regulation of macrophage and fibrocyte infiltration. Am J Pathol 2007;170:843-854.

52. Tredget EE, Nedelec B, Scott PG, et al. Hypertrophic scars, keloid, and contractures. The cellular and molecular basis for therapy. Surg Clin N Am 1997;77:701-730.

53. Scott PG, Ghahary A, Tredget EE. Molecular and cellular aspects of fibrosis following thermal injury. Hand Clin 2000;16:271-287.

54. Ehrlich HP, Desmouliere A, Diegelmann RF, et al. Morphological and immunochemical differences between keloid and hypertrophic scar. Am J Pathol 1994;145:105-113.

55. Santucci M, Borgognoni L, Reali UM, et al. Keloids and hypertrophic scars of Caucasians show distinctive morphologic and immunophenotypic profiles. Virchows Arch 2001;438:457-463.

56. Ghahary A, Shen YJ, Scott PG, et al. Enhanced expression of mRNA for transforming growth factor- $\boldsymbol{\beta}$, type I and III procollagen in human post-burn hypertrophic scar tissues. J Lab Clin Med 1993;122: 465-473.

57. Aiba S, Tagami H. Inverse correlation between CD34 expression and proline-4-hydroxylase immunoreactivity on spindle cells noted in hypertrophic scars and keloids. J Cutan Pathol 1997;24:65-69.

58. Hartert TV, Peebles Jr RS. Epidemiology of asthma: the year in review. Curr Opin Pulm Med 2000;6:4-9.

59. Kiley J, Smith R, Noel P. Asthma phenotypes. Curr Opin Pulm Med 2007;13:19-23.

60. Laitinen LA, Heino M, Laitinen $A$, et al. Damage of the airway epithelium and bronchial reactivity in patients with asthma. Am Rev Respir Dis 1985;131:599-606.

61. Shahana S, Bjornsson E, Ludviksdottir D, et al. Ultrastructure of bronchial biopsies from patients with allergic and non-allergic asthma. Respir Med 2005;99:429-443.

62. Mattoli S. Allergen-induced generation of mediators in the mucosa. Environ Health Perspect 2001;109(Suppl 4):553-557.

63. Marini M, Avoni E, Hollemborg J, et al. Cytokine mRNA profile and cell activation in bronchoalveolar lavage fluid from nonatopic patients with symptomatic asthma. Chest 1992;102:661-669.

64. Ackerman V, Marini M, Vittori E, et al. Detection of cytokines and their cell sources in bronchial biopsy specimens from asthmatic patients: relationship to atopic status, symptoms, and level of airway hyperresponsiveness. Chest 1994;105:687-696.

65. Elias JA, Zhu Z, Chupp G, et al. Airway remodeling in asthma. J Clin Invest 1999;104:1001-1006.

66. Bousquet J, Jeffery PK, Busse WW, et al. Asthma. From bronchoconstriction to airway inflammation and remodeling. Am J Respir Crit Care Med 2000;161:1720-1745.

67. Brewster CEP, Howarth PH, Djukanovic R, et al. Myofibroblasts and subepithelial fibrosis in bronchial asthma. Am J Respir Cell Mol Biol 1990;3:507-511.

68. Stewart AG, Tomlinson PR, Wilson J. Airway wall remodeling in asthma: a novel target for the development of anti-inflammatory drugs. Trend Pharmacol Sci 1993;14:275-279.

69. Gabbrielli S, Di Lollo S, Stanflin N, et al. Myofibroblasts and elastic and collagen fiber hyperplasia in the bronchial mucosa: a possible basis for the progressive irreversibility of airflow obstruction in asthma. Pathologica 1994;86:157-160.

70. Fish JE, Peters SP. Airway remodeling and persistent airway obstruction in asthma. J Allergy Clin Immunol 1999;104:509-516.

71. Rose Jr CE, Sung SJ, Fu SM. Significant involvement of CCL2 (MCP-1) in inflammatory disorders of the lung. Microcirculation 2003;10: 273-288.

72. Mattoli S, Schmidt M. Role in asthmatic lung disease. Chapter 6. In: Bucala R (ed). Fibrocytes: New Insights Into Tissue Repair and Systemic Fibroses. World Scientific Publishing Co. Pte. Ltd.: Singapore, 2007, pp 105-123.

73. O'Byrne PM, Dolovich J, Hargreave FE. Late asthmatic responses. Am Rev Respir Dis 1987;136:740-751.

74. Lemanske RF, Kaliner MA. Late phase allergic reactions. In: Middleton Jr E, Reed CE, Ellis EF, Adkinson NF, Yuninger JW, Busse WW (eds). Allergy: Principles and Practice, 4th edn. Mosby Yearbook: St Louis, 1993, pp 320-361.

75. Gizycki MJ, Adelroth E, Rogers A, et al. Myofibroblast involvement in the allergen-induced late response in mild atopic asthma. Am J Respir Cell Mol Biol 1997;16:664-673.

76. American Thoracic Society, European Respiratory Society. American Thoracic Society/European Respiratory Society international multidisciplinary consensus classification of the idiopathic interstitial pneumonias. Am J Respir Crit Care Med 2002;165:277-304.

77. Gross TJ, Hunninghake GW. Idiopatic pulmonary fibrosis. N Engl J Med 2001;345:517-525.

78. Mason RJ, Schwarz MI, Hunninghake GW, et al. NHLBI workshop summary, pharmacological therapy for idiopatic pulmonary fibrosis. Past, present and future. Am J Respir Crit Care Med 1999;160: 1771-1777.

79. Perez A, Rogers RM, Dauber JH. The prognosis of idiopatic pulmonary fibrosis. Am J Respir Cell Mol Biol 2003;29(Suppl 3):S19-S26.

80. Katzenstein AA, Myers JL. Idiopatic pulmonary fibrosis: clinical relevance of pathologic classification. Am J Respir Crit Care Med 1998:157:1301-1315.

81. King Jr TE, Schwarz MI, Brown K, et al. Idiopatic pulmonary fibrosis: relationship between histopathologic features and mortality. Am J Respir Crit Care Med 2001;164:1025-1032.

82. Choi ES, Pierce EM, Jakubzick C, et al. Focal interstitial CC chemokine receptor 7 (CCR7) expression in idiopatic interstitial pneumonia. J Clin Pathol 2006;59:28-39.

83. Mehrad B, Burdick MD, Zisman DA, et al. Circulating peripheral blood fibrocytes in human fibrotic interstitial lung disease. Biochem Biophys Res Commun 2007;353:104-108.

84. Pierce EM, Carpenter K, Jakubzick C, et al. Idiopatic pulmonary fibrosis fibroblasts migrate and proliferate to CC chemokine ligand 21. Eur Respir J 2007;29:1082-1093.

85. Galan A, Cowper SE, Bucala R. Nephrogenic systemic fibrosis (nephrogenic fibrosing dermopathy). Curr Opin Rheumatol 2006;18:614-617.

86. Grobner T. Gadolinium-a specific trigger for the development of nephrogenic fibrosing dermopathy and nephrogenic systemic fibrosis? Nephrol Dial Transplant 2006;21:1104-1108.

87. Boyd AS, Zic JA, Abraham JL. Gadolinium deposition in nephrogenic fibrosing dermopathy. J Am Acad Dermatol 2007;56:27-30.

88. Cowper SE, Su LD, Bhawan J, et al. Nephrogenic fibrosing dermopathy. Am J Dermatopathol 2001;23:383-393.

89. Ortonne N, Lipsker D, Chantrel F, et al. Presence of CD45RO+ CD34+ cells with collagen synthesis activity in nephrogenic fibrosing dermopathy: a new pathogenetic hypothesis. Br J Dermatol 2004;150:1050-1052

90. Jimenez SA, Artlett CM, Sandorfi N, et al. Dialysis-associated systemic fibrosis (nephrogenic fibrosing dermopathy): study of inflammatory cells and transforming growth factor $\boldsymbol{\beta} 1$ expression in affected skin. Arthritis Rheum 2004;50:2660-2666.

91. Mendoza FA, Artlett CM, Sandorfi N, et al. Description of twelve cases of nephrogenic fibrosing dermopathy and review of the literature. Semin Arthritis Rheum 2006;35:238-249.

92. Spencer A, Wilson S, Batchelor J, et al. Gadolinium chloride toxicity in the rat. Toxicol Pathol 1997;25:245-255.

93. Postlethwaite AE, Shigemitsu $H$, Kanangat $S$. Cellular origin of fibroblasts: possible implications for organ fibrosis in systemic sclerosis. Curr Opin Rheumatol 2004;16:733-738. 
94. Sakkas LI. New development in the pathogenesis of systemic sclerosis. Autoimmunity 2005;38:113-116.

95. Denton CP, Black CM, Abraham DJ. Mechanisms and consequences of fibrosis in systemic sclerosis. Nat Clin Pract Rheumatol 2006;2:134-144.

96. Kowal-Bielecka O. Targeting vascular disease in systemic sclerosis. Endocr Metab Immune Disord Drug Targets 2006;6:401-407.

97. Fleischmajer R, Perlish JS. Capillary alterations in scleroderma. J Am Acad Dermatol 1980;2:161-170.

98. Kraling BM, Maul GG, Jimenez SA. Mononuclear cell infiltrates in clinically involved skin from patients with systemic sclerosis of recent onset predominantly consist of monocytes/macrophages. Pathobiology 1995;63:48-56.

99. Kirk TZ, Mark ME, Chua CC, et al. Myofibroblasts from scleroderma skin synthesize elevated levels of collagen and tissue inhibitor of metalloproteinase (TIMP-1) with two forms of TIMP-1. J Biol Chem 1995;270:3423-3428.

100. Hasegawa M, Sato S, Takehara K. Augmented production of chemokines (monocyte chemotactic protein-1 (MCP-1), macrophage inflammatory protein-1alpha (MIP-1alpha) and MIP-1beta) in patients with systemic sclerosis: MCP-1 and MIP-1alpha may be involved in the development of pulmonary fibrosis. Clin Exp Immunol 1999;117:159-165.

101. Distler O, Pap T, Kowal-Bielecka O, et al. Overexpression of monocyte chemoattractant protein 1 in systemic sclerosis: role of plateletderived growth factor and effects on monocyte chemotaxis and collagen synthesis. Arthritis Rheum 2001;44:2665-2678.

102. Yamamoto T, Eckes B, Hartmann $\mathrm{K}$, et al. Expression of monocyte chemoattractant protein-1 in the lesional skin of systemic sclerosis. J Dermatol Sci 2001;26:133-139.

103. Odoux C, Crestani B, Lebrun G, et al. Endothelin-1 secretion by alveolar macrophages in systemic sclerosis. Am J Respir Crit Care Med 1997;156:1429-1435.

104. Kinsella MB, Smith EA, Miller KS, et al. Spontaneous production of fibronectin by alveolar macrophages in patients with scleroderma. Arthritis Rheum 1989;32:577-583.

105. Carulli MT, Ong VH, Ponticos $M$, et al. Chemokine receptor CCR2 expression by systemic sclerosis fibroblasts: evidence for autocrine regulation of myofibroblast differentiation. Arthritis Rheum 2005;52:3772-3782.

106. Caux C, Vanbervliet B, Massacrier C, et al. CD34 ${ }^{+}$hematopoietic progenitors from human cord blood differentiate along two independent dendritic cell pathways in response to GM-CSF+TNF $\alpha$. J Exp Med 1996;184:695-706.

107. Aiba S, Tabata N, Ohtani $\mathrm{H}$, et al. CD34 ${ }^{+}$spindle-shaped cells selectively disappear from the skin lesion of scleroderma. Arch Dermatol 1994;130:593-597.

108. Murdoch C, Giannoudis A, Lewis CE. Mechanisms regulating the recruitment of macrophages into hypoxic areas of tumors and other ischemic tissues. Blood 2004;104:2224-2234.

109. Ross R. Atherosclerosis-an inflammatory disease. N Engl J Med 1999;340:115-126.

110. Traub O, Berk BC. Laminar shear stress: mechanisms by which endothelial cells transducer an atheroprotective force. Arterioscler Thromb Vasc Biol 1998;18:677-685.

111. Ross R. Cell biology of atherosclerosis. Annu Rev Physiol 1995;57:791-804

112. Stary $H C$, Chandler $A B$, Glagov $S$, et al. A definition of initial, fatty streak, and intermediate lesions of atherosclerosis. A report from the
Committee on Vascular lesions of the Council on Arteriosclerosis, American Heart Association. Arterioscler Thromb Vasc Biol 1994;14:840-856.

113. Stary $H C$, Chandler AB, Dinsmore RE, et al. A definition of advanced types of atherosclerotic lesions and a histological classification of atherosclerosis. A report from the Committee on Vascular Lesions of the Council on Arteriosclerosis, American Heart Association. Arterioscler Thromb Vasc Biol 1995;15:1512-1531.

114. Andreeva ER, Pugach IM, Orekhov AN. Collagen-synthesizing cells in initial and advanced atherosclerosis lesions of human aorta. Atherosclerosis 1997;130:133-142.

115. Pasterkamp G, de Kleijn DP, Borst C. Arterial remodeling in atherosclerosis, restenosis and after alteration of blood flow: potential mechanisms and clinical implications. Cardiovasc Res 2000;45:843-852

116. Ross R, Glomset JA. Atherosclerosis and the arterial smooth muscle cell: proliferation of smooth muscle is a key event in the genesis of the lesions of atherosclerosis. Science 1973;180:1332-1339.

117. Fletcher JP, Guiffre A, Medbury $\mathrm{H}$. Fibrocytes in atherosclerosis: VS022. ANZ Journal of Surgery 2005;75(Suppl):A119.

118. Medbury H. Role of fibrocytes in atherogenesis. Chapter 10. In: Bucala R (ed). Fibrocytes: New Insights Into Tissue Repair and Systemic Fibroses. World Scientific Publishing Co. Pte. Ltd.: Singapore, 2007, pp 175-194.

119. Andreeva ER, Pugach IM, Orekhov AN. Subendothelial smooth muscle cells of human aorta express macrophage antigen in situ and in vitro. Atherosclerosis 1997;135:19-27.

120. Swirski FK, Libby $P$, Aikawa $E$, et al. Ly- $6 C^{\text {high }}$ monocytes dominate hypercholesterolemia-associated monocytosis and give rise to macrophages in atheromata. J Clin Invest 2007;117:195-205.

121. Deo R, Khera A, McGuire DK, et al. Association among plasma levels of monocyte chemoattractant protein-1, traditional cardiovascular risk factors, and subclinical atherosclerosis. J Am Coll Cardiol 2004;44:1812-1818.

122. McDermott $\mathrm{DH}$, Yang $\mathrm{Q}$, Kathiresan $\mathrm{S}$, et al. CCL2 polymorphisms are associated with serum monocyte chemoattractant protein-1 levels and myocardial infarction in the Framingham Heart Study. Circulation 2005;112:1113-1120.

123. Davies MJ, Richardson PD, Woolf N, et al. Risk of thrombosis in human atherosclerotic plaques: role of extracellular lipid, macrophage, and smooth muscle cell content. Br Heart J 1993;69:377-381.

124. Lutgens $E$, Gijbels $M$, Smook $M$, et al. Transforming growth factorbeta mediates balance between inflammation and fibrosis during plaque progression. Arterioscler Thromb Vasc Biol 2002;22: 975-982.

125. Ishii G, Sangai T, Oda T, et al. Bone-marrow-derived myofibroblasts contribute to the cancer-induced stromal reaction. Biochem Biophys Res Commun 2003;309:232-240.

126. Direkze NC, Hodivala-Dilke K, Jeffery R, et al. Bone marrow contribution to tumor-associated myofibroblasts and fibroblasts. Cancer Res 2004;64:8492-8495.

127. Bridle KR, Crawford DH, Powell LW, et al. Role of myofibroblasts in tumour encapsulation of hepatocellular carcinoma in haemochromatosis. Liver 2001;21:96-104.

128. Olson T, Ley K. Chemokines and chemokine receptors in leukocyte trafficking. Am J Physiol Regulatory Integrative Comp Physiol 2002;283:R7-R28. 